\title{
High Fat Diet and Inflammation - Modulation of Haptoglobin Level in Rat Brain
}

\begin{abstract}
Maria Stefania Spagnuolo', Maria Pina Mollica², Bernardetta Maresca², Gina Cavaliere², Carolina Cefaliello², Giovanna Trinchese ${ }^{2}$, Rosaria Scudiero ${ }^{2}$, Marianna Crispino ${ }^{2}$ and Luisa Cigliano ${ }^{2 *}$
\end{abstract}

${ }^{1}$ Laboratory of Animal Physiology, Department of Bio-Agrofood Science, Institute for Animal Production System in
Mediterranean Environment, National Research Council, Naples, Italy, ${ }^{2}$ Department of Biology, University of Naples
Federico II, Naples, Italy

Obesity and dietary fats are well known risk factors for the pathogenesis of neurodegenerative diseases. The analysis of specific markers, whose brain level can be affected by diet, might contribute to unveil the intersection between inflammation/obesity and neurodegeneration. Haptoglobin (Hpt) is an acute phase protein, which acts as antioxidant by binding free haemoglobin $(\mathrm{Hb})$, thus neutralizing its pro-oxidative action. We previously demonstrated that Hpt plays critical functions in brain, modulating cholesterol trafficking in neuroblastoma cell lines, beta-amyloid $(A \beta)$ uptake by astrocyte, and limiting $A \beta$ toxicity on these cells. A major aim of this study was to evaluate whether a long term (12 or 24 weeks) high-fat diet (HFD) influences $\mathrm{Hpt}$ and $\mathrm{Hb}$ expression in rat hippocampus. We also assessed the development of obesity-induced inflammation by measuring hippocampal level of TNF-alpha, and the extent of protein oxidation by titrating nitro-tyrosine ( $\mathrm{N}$-Tyr). Hpt concentration was lower $(p<0.001)$ in hippocampus of HFD rats than in control animals, both in the 12 and in the 24 weeks fed groups. HFD was also associated in hippocampus with the increase of Hb level $(p<0.01)$, inflammation and protein oxidative modification, as evidenced by the increase in the concentration of TNF-alpha and nitro-tyrosine. In fact, TNFalpha concentration was higher in rats receiving HFD for $12(p<0.01)$ or 24 weeks $(p<0.001)$ compared to those receiving the control diet. $\mathrm{N}$-Tyr concentration was more elevated in hippocampus of HFD than in control rats in both 12 weeks $(p=0.04)$ and 24 weeks groups $(p=0.01)$, and a positive correlation between $\mathrm{Hb}$ and $\mathrm{N}$-Tyr concentration was found in each group. Finally, we found that the treatment of the human glioblastoma-astrocytoma cell line U-87 MG with cholesterol and fatty acids, such as palmitic and linoleic acid, significantly impairs $(p<0.001)$ Hpt secretion in the extracellular compartment. We hypothesize that the HFD-dependent decrease of Hpt in hippocampus, as associated with $\mathrm{Hb}$ increase, might enhance the oxidative stress induced by free $\mathrm{Hb}$. Altogether our data, identifying $\mathrm{Hpt}$ as a molecule modulated in the brain by dietary fats, may represent one of the first steps in the comprehension of the molecular mechanisms underlying the diet-related effects in the nervous system.

Keywords: haptoglobin, hemoglobin, TNF-alpha, nitro-tyrosine, high-fat diet, human astrocytoma cell line U-87 MG, rat, hippocampus 


\section{INTRODUCTION}

Obesity relationship with various health problems has been well described in several recent studies (Haslam and James, 2005; Malnick and Knobler, 2006). In the last decade, obesity, and dietary fats were identified as risk factors for cognitive decline and various types of neurodegenerative dementias (Kalmijn, 2000; Solfrizzi et al., 2003; Gustafson, 2008; Craft, 2009; Sellbom and Gunstad, 2012). Indeed, human epidemiological studies revealed a correlation between a high-fat diet (HFD) and cognitive impairment (Elias et al., 2003; Morris et al., 2004; Zhang et al., 2006), as well as between body mass index and Alzheimer's Disease (AD) development (Benito-León et al., 2013; Reinert et al., 2013). In particular, it was demonstrated that a diet enriched with saturated and trans fatty acids is associated with increased risk for AD (Kalmijn et al., 1997; Luchsinger et al., 2002; Morris et al., 2003). Biological mechanisms underlying damaging effects of obesity on brain are still poorly understood, although studies on experimental models and humans have shown that obesity is associated with increased brain oxidative stress (Mattson et al., 2003; Zhang et al., 2005; Souza et al., 2007) and neuroinflammation (Thirumangalakudi et al., 2008; Pistell et al., 2010; Freeman et al., 2014), both implicated in the pathogenesis of neurodegenerative diseases (Freeman et al., 2014). Therefore, the identification of molecules that can be modulated by dietary fats, might contribute to clarify the specific obesity-related effects on brain physiology and pathology.

In this frame, we demonstrated that Haptoglobin (Hpt), an acute-phase protein of inflammation, binds Apolipoprotein $\mathrm{E}$ (ApoE), influencing ApoE-mediated cholesterol trafficking in blood (Cigliano et al., 2009) and in neuroblastoma cell lines (Spagnuolo et al., 2014a). Further, we have recently reported that Hpt also affects ApoE-dependent 24(S)-hydroxycholesterol esterification (La Marca et al., 2014), a key step for cholesterol removal from the brain.

Hpt is synthesized primarily by hepatocytes, and in white adipose tissue (WAT; Friedrichs et al., 1995; Quaye, 2008), and its blood levels vary according to the volume of adiposity in the body (Chiellini et al., 2004). Hpt is so far known for its ability to bind free Haemoglobin ( $\mathrm{Hb})$, to transport it to the liver and therefore to limit the pro-oxidative action of free $\mathrm{Hb}$ (Quaye, 2008). Also, we previously demonstrated that Hpt acts as antioxidant, by preventing Apolipoprotein A-I (ApoA-I) and ApoE oxidation by free radical species (Salvatore et al., 2007, 2009). Although the presence of Hpt in the brain was firstly suggested as a marker of blood-brain barrier (BBB) dysfunction (Chamoun et al., 2001), different studies demonstrated that Hpt is produced in this compartment, in response to stress stimuli (Lee et al., 2002; Borsody et al., 2006; Zhao et al., 2009), as well as by human astrocytes in vitro (Maresca et al., 2015). Further, increased Hpt concentration was found in cerebrospinal fluid (CSF) from AD patients (Johnson et al., 1992; Yerbury and Wilson, 2010), and increased oxidation of this protein was described in plasma of AD patients (Cocciolo et al., 2012). In addition, we recently demonstrated that $\mathrm{Hpt}$ increases with the age in rat hippocampus as well as in human CSF (Spagnuolo et al., 2014a).
Beyond its Hb-binding function, $\mathrm{Hpt}$ also acts as extracellular chaperone, by inhibiting amyloid beta $(\mathrm{A} \beta)$ fibril formation in vitro (Wilson et al., 2008; Yerbury et al., 2009), colocalizes with amyloid plaques in AD (Powers et al., 1981; Veerhuis et al., 2003; Yerbury et al., 2005), and was proposed as potential biomarker of $\mathrm{AD}$ (Thambisetty, 2010). In addition, we recently provided evidence that Hpt, due to its ability to bind both $A p o E$ and $A \beta$, promotes the formation of the ApoE/A $\beta$ complex (Spagnuolo et al., 2014b), which is crucial to prevent or limit $A \beta$ neurotoxicity and to promote its clearance. Hpt modulation of $A \beta$ uptake by astrocyte and its activity of limiting $A \beta$ toxicity in these cells was also reported (Maresca et al., 2015).

As dietary composition can negatively affect hippocampal function (Hsu and Kanoski, 2014), and Hpt modulates ApoEdependent cholesterol homeostasis in the brain (Spagnuolo et al., 2014a), a major aim of this study was to evaluate whether a long term high fat diet influences Hpt expression in rat hippocampus. This brain region, crucial for learning and memory, is considered one of the most vulnerable sites in early $\mathrm{AD}$ and other neurodegenerative diseases development (Gómez-Isla et al., 1996; Price et al., 2001), and is particularly susceptible to disruption by dietary factors. In addition, in view of the previously described Hpt antioxidant function (Salvatore et al., 2007, 2009; Quaye, 2008), we also investigated whether diet-dependent Hpt changes are associated with inflammation and with changes in the level of nitro-tyrosine (N-Tyr), here selected as marker of the extent of protein oxidative modification.

\section{MATERIALS AND METHODS}

\section{Materials}

Bovine serum albumin fraction V (BSA), human $\mathrm{Hb}$, phosphatidylcholine (PC) from egg yolk, 2-linoleoyl-1palmitoyl-sn-glycero-3-phosphocholine (LP), rabbit anti-human Hpt IgG, mouse anti- $\beta$ actin IgG, goat anti-rabbit Horseradish Peroxidase-conjugated IgG (GAR-HRP), goat anti-mouse Horseradish Peroxidase-conjugated IgG (GAM-HRP), rabbit anti-human $\mathrm{Hb}$, mouse anti-human Hpt, and MTT [3-(4,5dimethylthiazol-2-yl)-2,5-diphenyltetrazolium bromide], were purchased from Sigma-Aldrich (St. Louis, MO, USA). Rabbit anti-N-Tyr of Covalab was purchased by Vincibiochem (Vinci, Italy). Rabbit anti-rat Hpt was from ICL Lab (distributed by Prodotti Gianni, Milano, Italy). The dye reagent for protein titration, enhanced chemiluminescence (ECL) reagents, and the polyvinylidene difluoride (PVDF) membrane were from Bio-Rad (Bio-Rad, Hercules, CA, USA). Polystyrene 96-wells ELISA MaxiSorp plates, with high affinity to proteins with mixed hydrophilic/hydrophobic domains, were purchased from Nunc (Roskilde, Denmark). Kodak Biomax light film, Sephacryl S-200, CNBr-activated Sepharose 4 Fast Flow and Blue Sepharose 6 Fast Flow resins were from GE-Healthcare Life Sciences (Milano, Italy). DMEM, fetal bovine serum (FBS), L-glutamine, penicillin and streptomycin were from Gibco (Life Technologies Italy, Monza, Italy). Cell culture flasks ( 25 and $75 \mathrm{~cm}^{2}$ ), 6 and 96-well cell culture plates, and sterile pipettes of Beckton-Dickinson (Milan, Italy) were used. 


\section{Animal and Experimental Design}

Two months old male Wistar rats (Charles River, Calco, Como, Italy), with similar body weight ( $340 \pm 10 \mathrm{~g})$, were individually caged in a temperature-controlled room $\left(23 \pm 1^{\circ} \mathrm{C}\right)$ with a 12 -h light/12-h dark cycle. Animals were housed in the Animal Care Facility at the Department of Biology, with water ad libitum, and they were randomly divided into four experimental groups. Two groups (control) received a standard diet (control diet, CD; $10.6 \%$ fat J/J; Mucedola 4RF21; Settimo Milanese, Milan, Italy) for $12(N=8$; CD 12) or $24(N=7$; CD 24) weeks. The other two groups (high-fat) received a HFD rich in lard (40\% fat J/J) for $12(N=6$; HFD 12) or $24(N=7$; HFD 24$)$ weeks. The composition of all dietary regimens is reported in Table 1. During the treatments, the body weight and food intake were monitored daily to calculate weight gain and gross energy intake. Spilled food were collected daily for precise food intake calculation.

At the end of the experimental period, animals of each group were anesthetized by chloral hydrate $(40 \mathrm{mg} / 100 \mathrm{~g}$ body wt) and killed by decapitation. Blood was collected and serum was obtained by centrifuging at $1000 \times g$ for $10 \mathrm{~min}$ before storing at $-80^{\circ} \mathrm{C}$ until the biochemical measurements.

The brains were quickly removed and hippocampus was dissected on ice. Samples were snap frozen in liquid nitrogen immediately and stored at $-80^{\circ} \mathrm{C}$ for subsequent RNA and protein isolation.

The evaluation of fat and protein content in animal carcasses was conducted according to a published protocol (Iossa et al., 2002).

This study was carried out in strict accordance with the Institutional Guidelines and complied with the Italian D.L. no.116 of January 27, 1992 of Ministero della Salute and associated guidelines in the European Communities Council Directive of November 24, 1986 (86/609/ECC). All animal procedures reported herein were approved by the Institutional Animal Care and Use Committee (CSV) of University of Naples Federico II. All efforts were made to minimize animal suffering and to reduce the number of animals used.

TABLE 1 | Diet composition.

\begin{tabular}{|c|c|c|}
\hline & Control diet & $\begin{array}{l}\text { High lard diet } \\
\text { (g/100g diet) }\end{array}$ \\
\hline Standard feed & 100 & 51.3 \\
\hline Casein $^{\mathrm{a}} \mathrm{g}$ & - & 9.25 \\
\hline Lard g & - & 21.8 \\
\hline Sunflower oil g & - & 1.24 \\
\hline AIN 76 mineral mix ${ }^{b} \mathrm{~g}$ & - & 1.46 \\
\hline AIN 76 Vitamin mix $\mathrm{g}$ & - & 0.42 \\
\hline Choline bitartrato & - & 0.08 \\
\hline Methionine g & - & 0.12 \\
\hline Energy density kJ/g diet & 15.88 & 20.00 \\
\hline Protein \% & 29 & 29 \\
\hline Lipid \% & 10.6 & 40 \\
\hline Carbohydrate \% & 60.4 & 31 \\
\hline
\end{tabular}

${ }^{\mathrm{a}}$ Purified high-nitrogen casein containing $88 \%$ protein, ${ }^{\mathrm{b}}$ American Institute of Nutrition (1977), ' ${ }^{c}$ American Institute of Nutrition (1980).

\section{Cell Culture}

The human glioblastoma-astrocytoma cell line U-87 MG was kindly provided by the Institute of Genetics and Biophysics (CNR, Naples, Italy). Cells $(500,000)$ were seeded in $50 \mathrm{ml}$ tissue culture flasks (25 $\mathrm{cm}^{2}$ surface), and grown in DMEM supplemented with $10 \%$ FBS, $2 \mathrm{mM}$ L-glutamine, $100 \mathrm{U} / \mathrm{ml}$ penicillin, and $100 \mu \mathrm{g} / \mathrm{ml}$ streptomycin (complete medium) at $37^{\circ} \mathrm{C}$ under humidified atmosphere of $5 \% \mathrm{CO}_{2}$ in air. The medium was changed twice a week, and cells were sub-cultivated when confluent.

U-87 MG cells were seeded into 6-well plates (at 400,000 cells/well density) in complete medium, and incubated $\left(37^{\circ} \mathrm{C}, 5 \%\right.$ $\mathrm{CO}_{2}$ ) for $20 \mathrm{~h}$. After removal of the medium, and washing with DMEM, the cells were used in the assays described below.

\section{Titration of Serum Hpt}

Haptoglobin concentration in individual samples was measured by ELISA. Samples were diluted (1:1000, 1:3000, 1:9000, 1:20000, and 1:40000) with coating buffer $\left(7 \mathrm{mM} \mathrm{Na} \mathrm{CO}_{3}, 17 \mathrm{mM}\right.$ $\left.\mathrm{NaHCO}_{3}, 1.5 \mathrm{mM} \mathrm{NaN}_{3}, \mathrm{pH} 9.6\right)$, and aliquots $(50 \mu \mathrm{l})$ were then incubated in the wells of a microtiter plate (Immuno MaxiSorp; overnight, $\left.4^{\circ} \mathrm{C}\right)$. After four washes by T-TBS $(130 \mathrm{mM} \mathrm{NaCl}$, $20 \mathrm{mM}$ Tris- $\mathrm{HCl}, 0.05 \%$ Tween $20, \mathrm{pH}$ 7.4) and four washes by high salt TBS $(500 \mathrm{mM} \mathrm{NaCl}$ in $20 \mathrm{mM}$ Tris- $\mathrm{HCl}$ at $\mathrm{pH}$ 7.4), the wells were blocked with TBS containing $0.5 \%$ BSA $\left(1 \mathrm{~h}, 37^{\circ} \mathrm{C}\right)$. After washing, the wells were incubated $\left(1 \mathrm{~h}, 37^{\circ} \mathrm{C}\right)$ with $60 \mu \mathrm{l}$ of rabbit anti-rat IgG (1: 500 dilution in T-TBS containing $0.25 \%$ BSA) followed by $60 \mu \mathrm{l}$ of GAR-HRP IgG (1:3000 dilution). Peroxidase-catalyzed color development from $o$-phenylenediamine was measured at $492 \mathrm{~nm}$. The calibration curve was obtained by assaying the immunoreactivity of $2,1,0.5$, $0.25,0.1,0.05,0.03 \mathrm{ng}$ of purified Hpt 1-1.

\section{Analysis of TNF-Alpha Concentration in Hippocampus}

For quantification of TNF-alpha, proteins were extracted from slices hippocampus by homogenizing frozen tissues in lysis buffer (100 mM Tris/HCl, pH 7.0, $1 \mathrm{M} \mathrm{NaCl}, 4$ mM EDTA.Na $2,2 \%$ Triton X-100, $0.1 \%$ sodium azide) containing Tissue Protease Inhibitor Cocktail (Sigma-Aldrich, 1:1000, v/v). Hippocampal homogenates were centrifuged at $14000 \times g$ for $30 \mathrm{~min}$ at $4^{\circ} \mathrm{C}$ and soluble samples were used for ELISA. In detail TNFalpha concentration was titrated by sandwich ELISA, using the TNF-alpha Duo-Set kit (R\&D, distributed by DBA Italia, Milan, Italy), essentially according to the manufacturer instructions. Each hippocampus homogenate was diluted (1:10, 1:30, and 1:60) in the assay. Data were reported as pg of TNF-alpha per mg of proteins.

\section{Real-Time PCR Analysis}

Total RNA was extracted according to the TRI-Reagent (SigmaAldrich) protocol. The concentration and purity of RNA samples were determined by UV absorbance spectrophotometry. RNA integrity was checked on $1.2 \%$ agarose gel electrophoresis. First-strand cDNA was synthesized from each total RNA $(1 \mu \mathrm{g})$ using the QuantiTect reverse transcription kit (Qiagen). The 
Real Time PCR reactions were carried out in quadruplicate in an Applied Biosystems 7500 Real Time System by using the Power SYBR Green Master Mix PCR (Applied Biosystems). Each SYBR Green reaction (20 $\mu$ l total volume) contained $2 \mu \mathrm{l}$ of 1:1 diluted cDNA as template. For internal standard control, the expression of $\beta$-actin gene was quantified. Primer sequences were designed using Primer Express software (Applied Biosystems). Hpt primers were designed on the exon junction 278/279 (forward primer) on template NM012582.2 (forward primer, 5' - TGAGGCAGTGTGTGGGAAGCCC-3'; reverse primer, $5^{\prime}$ - TGTGGCCCCAGTGGTGAGTCC-3'); $\beta$-actin primers were designed on the exon junction $75 / 76$ (forward primer) on template NM031144.2 (forward primer, 5' - ACCCGCCACCAGTTCGCCAT-3'; reverse primer, 5' CGGCCCACGATGGAGGGGAA-3'). Amplicons were 128136 bp long. The PCR was performed under the following conditions: holding stage of $95^{\circ} \mathrm{C}$ per $10^{\prime}$; cycling tage (45 cycles): $95^{\circ} \mathrm{C} \times 10 \mathrm{~s}-60^{\circ} \mathrm{C} \times 10 \mathrm{~s}-72^{\circ} \mathrm{C} \times 10 \mathrm{~s}$; melting stage: $95^{\circ} \mathrm{C} \times 5 \mathrm{~s}-65^{\circ} \mathrm{C} \times 1 \mathrm{~m}-95^{\circ} \mathrm{C} \times 30 \mathrm{~s}-40^{\circ} \mathrm{C} \times 30 \mathrm{~s}$.

PCR amplification efficiencies were determined and $\Delta \Delta \mathrm{CT}$ relative quantification was done using $\beta$-actin gene expression as internal control to normalize the results.

\section{Electrophoresis and Western Blotting of Hippocampal Homogenates}

Proteins were extracted from hippocampus by homogenizing frozen tissues $\left(-80^{\circ} \mathrm{C}\right)$ in ten volumes $(\mathrm{w} / \mathrm{v})$ of cold RIPA buffer (150 mM NaCl, $50 \mathrm{mM}$ Tris- $\mathrm{HCl}, 1 \% \mathrm{NP}-40,0.5 \%$ sodium deoxycholate, $0.1 \%$ SDS, $\mathrm{pH}$ 8) containing Tissue Protease Inhibitor Cocktail (Sigma-Aldrich, 1:1000, v/v). Homogenates were then centrifuged $\left(14,000 \mathrm{~g}, 45 \mathrm{~min}, 4^{\circ} \mathrm{C}\right)$ and protein concentration of supernatants was measured according to a published procedure (Bradford, 1976).

Aliquots $(50 \mu \mathrm{g})$ of each homogenate were fractionated by electrophoresis in denaturing and reducing condition on $12.5 \%$ polyacrylamide gel, as previously reported (Spagnuolo et al., 2014a). After electrophoresis, proteins were transferred onto PVDF membrane ( $1 \mathrm{~h}$, under electric field), the membrane was rinsed in T-TBS and then blocked with T-TBS containing $5 \%$ non-fat milk (overnight, $4^{\circ} \mathrm{C}$ ). The membrane was then incubated $\left(1 \mathrm{~h}, 37^{\circ} \mathrm{C}\right)$ with rabbit anti-rat $\mathrm{Hpt}(1: 500$ dilution in T-TBS containing $0.25 \%$ non-fat milk) followed by GARHRP IgG (1: 500 dilution; $1 \mathrm{~h}, 37^{\circ} \mathrm{C}$ ). The immunocomplexes were detected by the ECL detection system, using luminol as substrate, according to the manufacturer protocol. Quantitative densitometry of $\mathrm{Hpt}$ was then carried out by analyzing the digital images of membranes by the Gel-Pro Analyzer software (Media Cybernetics, Silver Spring, MA, USA). Band intensities were calculated as integrated optical density (IOD).

After Hpt detection, the membrane was extensively washed with T-TBS and then submerged in stripping buffer $(100 \mathrm{mM}$ $\beta$-mercaptoethanol, 2\% SDS, $62.5 \mathrm{mM}$ Tris- $\mathrm{HCl}, \mathrm{pH}$ 6.7; $45 \mathrm{~min}$, $50^{\circ} \mathrm{C}$ ) for reprobing with anti- $\beta$-actin. After washing with T-TBS, the membrane was incubated $\left(1 \mathrm{~h}, 37^{\circ} \mathrm{C}\right)$ with mouse anti- $\beta$-actin IgG (1:2,000 dilution), followed by GAM-HRP IgG (1:10,000 dilution; $\left.1 \mathrm{~h}, 37^{\circ} \mathrm{C}\right)$. The immunocomplexes were detected by the
ECL detection system, and densitometric analysis of the signal was carried out as above. Hpt concentration was then quantified after normalization with $\beta$-actin, and results were expressed as arbitrary units.

\section{Analysis of $\mathrm{Hb}$ Concentration in Rat Hippocampus}

Haemoglobin concentration in individual samples was measured by ELISA. Samples were diluted (1:100, 1:400, 1:600, and 1:1000) with coating buffer, and then incubated in the wells of a microtiter plate (overnight, $4^{\circ} \mathrm{C}$ ). After four washes by T-TBS and four washes by high salt TBS, the wells were blocked as above described $\left(1 \mathrm{~h}, 37^{\circ} \mathrm{C}\right)$. After washing, the wells were incubated $\left(1 \mathrm{~h}, 37^{\circ} \mathrm{C}\right)$ with $60 \mu \mathrm{l}$ of rabbit anti-human $\mathrm{Hb}$ IgG (1: 500 dilution in T-TBS containing $0.25 \%$ BSA) followed by $60 \mu \mathrm{l}$ of GAR-HRP IgG (1:5000 dilution). Peroxidase-catalyzed color development from $o$-phenylenediamine was measured at $492 \mathrm{~nm}$. The calibration curve was obtained by assaying the immunoreactivity of $1,0.5,0.25,0.1$, and $0.05 \mathrm{ng}$ of commercial $\mathrm{Hb}$ standard. Data were reported as $\mu \mathrm{g}$ of $\mathrm{Hb}$ per $\mathrm{mg}$ of proteins.

\section{Titration of Nitro-Tyrosine (N-Tyr) in Rat Hippocampus}

$\mathrm{N}$-Tyr in individual samples was quantified by ELISA. Samples were diluted $(1: 100,1: 250,1: 500$, and 1:1000) with coating buffer, and aliquots $(50 \mu \mathrm{l})$ were then incubated in the wells of a microtiter plate (overnight, $4^{\circ} \mathrm{C}$ ). After four washes by T-TBS and four washes by high salt TBS the wells were blocked with TBS containing $0.5 \%$ BSA $\left(1 \mathrm{~h}, 37^{\circ} \mathrm{C}\right)$. After washing, the wells were incubated $\left(1 \mathrm{~h}, 37^{\circ} \mathrm{C}\right)$ with $50 \mu \mathrm{l}$ of rabbit anti-N-Tyr (1: 1000 dilution in T-TBS containing $0.25 \%$ BSA) followed by $60 \mu \mathrm{l}$ of GAR-HRP IgG (1:5000 dilution). Peroxidase-catalyzed color development from $o$-phenylenediamine was measured at $492 \mathrm{~nm}$. Data were reported as OD per mg of proteins.

\section{Hpt Secretion by U-87 MG Cell Line}

U-87 MG were seeded into six well-plate (400,000 cells/well) in complete medium and cultured for $20 \mathrm{~h}$. After medium removal, cells were rinsed with DMEM, and incubated $(20 \mathrm{~h}$, $37^{\circ} \mathrm{C}$ ) in DMEM containing different amounts of free cholesterol $(0,1.5,3,6$, or $12 \mu \mathrm{g} / \mathrm{ml})$, or liposome embedded 2-linoleoyl1-palmitoyl-sn-glycero-3-phosphocholine (Lipo-LP; 0, 0.1, 0.3, 0.9 , or $3 \mu \mathrm{M}$ ), or liposome-embedded PC (Lipo-PC; 0, 0.3, 0.9, 1.6 , or $3 \mu \mathrm{M})$. At the end of incubation, media samples were collected, supplemented with Tissue Protease Inhibitor Cocktail (Sigma-Aldrich, 1:500, v/v), cleared of any cellular debris by centrifugation $(400 \mathrm{~g}, 10 \mathrm{~min}$ ), and finally immunoprecipitated with $1 \mu \mathrm{g}$ of rabbit anti-human $\mathrm{Hpt}$ (overnight, $4^{\circ} \mathrm{C}$ ). Twenty microliter of protein G Plus/protein A Agarose Suspension were added to each sample, and a further incubation $\left(2 \mathrm{~h}, 4^{\circ} \mathrm{C}\right)$ was carried out.

The cells were extensively washed with DMEM, detached by treatment $\left(5 \mathrm{~min}, 37^{\circ} \mathrm{C}\right)$ with $500 \mu \mathrm{l}$ of trypsin (TrypLE Express, Gibco), and finally lysed with $0.3 \mathrm{~mL}$ of RIPA buffer $(150 \mathrm{mM}$ $\mathrm{NaCl}, 50 \mathrm{mM}$ Tris- $\mathrm{HCl}, 0.5 \% \mathrm{NP}-40,0.5 \%$ sodium deoxycholate, 
$0.1 \%$ SDS, pH 8) containing the protease inhibitor cocktail (1:200, $\mathrm{v} / \mathrm{v})$. The lysates were centrifuged $\left(12000 \mathrm{~g}, 30 \mathrm{~min}, 4^{\circ} \mathrm{C}\right)$ and then analyzed for their protein concentration (Bradford, 1976).

Immunoprecipitates were analyzed by $12.5 \%$ SDS-PAGE, and Western blotting for revealing Hpt. In detail, after protein transfer onto PVDF membrane, the blocking was performed as above described, and Hpt was revealed by incubation (overnight, $4^{\circ} \mathrm{C}$ ) with mouse anti-human Hpt IgG (1: 500 dilution), followed by GAM-HRP IgG (1: 8000 dilution; $1 \mathrm{~h}, 37^{\circ} \mathrm{C}$ ) and ECL staining. Quantitative densitometry of the bands was carried out by analyzing digital images of X-ray films exposed to immunostained membranes. In particular, the images were analyzed by the Gel-Pro Analyzer software (Media Cybernetics, Silver Spring, MA, USA), and the intensities of the bands were recorded as peaks on densitograms. The peak areas were measured and expressed as IOD, namely IOD. Band intensities (IOD) per mg of cell protein were then calculated.

Liposomes containing PC or LP were prepared by the cholate dialysis procedure as previously reported (Chen and Albers, 1982).

\section{Cell Viability Assay}

In order to evaluate the effect of cholesterol, Lipo-LP, or LipoPC on survival of U-87 MG, cells were seeded into 96-well plate (8,000 cells per well), as above described, and cultured for $20 \mathrm{~h}$ in complete medium. After medium removal, cells were rinsed with DMEM, and incubated $\left(20 \mathrm{~h}, 37^{\circ} \mathrm{C}\right)$ in DMEM containing different amounts of free cholesterol $(0,1.5,3,6,12,24$, or $40 \mu \mathrm{g} / \mathrm{ml}$ ), or Lipo-LP (; $0,0.1,0.3,0.9,3,6$, or $12 \mu \mathrm{M})$, LipoPC $(0,0.3,0.9,1.6,3,6$, or $12 \mu \mathrm{M})$. The medium was then removed and cell survival was evaluated by MTT reduction assay. In detail, $100 \mu \mathrm{l}$ of MTT $(0.5 \mathrm{mg} / \mathrm{ml}$ in DMEM without Phenol red) were added to each well, and the incubation was carried out for $3 \mathrm{~h}$ at $37^{\circ} \mathrm{C}$. One hundred microliters of a solution containing $0.1 \mathrm{M} \mathrm{HCl}$ in isopropanol were then added to each well, and, after $30 \mathrm{~min}$, the absorbance at $595 \mathrm{~nm}$ was measured with a BioRad 3350 microplate reader. The data were expressed as viability percentage, assuming the absorbance value from untreated cells as $100 \%$.

\section{Statistical Analysis}

In all experiments samples were processed in triplicate, and data were expressed as mean value \pm SEM. The program "GraphPad
Prism 5.01" (GraphPad Software, San Diego, CA, USA) was used to perform regression analysis, Student's $t$-test, for comparing two groups of data, and one-way ANOVA, followed by Tukey's test, for multiple group comparisons. $P<0.05$ was set as indicating significance.

\section{RESULTS}

\section{General Features of High Fat Diet Fed Rats}

As shown in Table 2, animals fed HFD showed a significantly higher body weight compared to control groups, both after 12 $(574.0 \pm 16.6 \mathrm{~g}$ vs. $640.0 \pm 22.2 \mathrm{~g}, p=0.045)$ and 24 weeks $(614.3 \pm 13.1 \mathrm{~g}$ vs. $714.5 \pm 20.1 \mathrm{~g}, p=0.045)$. In addition, weight gain was higher in the HFD group compared to CD group both after $12(296.2 \pm 21.6 \mathrm{~g}$ vs. $231.5 \pm 15.8 \mathrm{~g} ; 86 \pm 6.2 \%$ vs. $66.1 \pm 4.7 \% ; p=0.04)$ and 24 weeks $(372 \pm 20.6 \mathrm{~g}$ vs. $269 \pm 11.8 \mathrm{~g} ; 108.6 \pm 6.6 \%$ vs. $77.7 \pm 3.15 \% ; p=0.0004)$. The diet-dependent increase in body weight was also affected by the duration of diet administration $(p<0.05)$, in the HFD group $(p=0.03)$, while was not affected by the length of treatment in the control group (Table 2). Further, the analysis of body composition after 12 weeks of treatment revealed that lipid content was higher in HFD than in CD rats $(33.06 \pm 1.13 \%$ vs. $15.18 \pm 0.38 \% ; p<0.001)$. Water and protein contents were significantly lower in HFD rats compared to CD rats (water, $48.46 \pm 1.08 \%$ vs. $63.22 \pm 0.44 \%, p<0.001$; protein, $12.82 \pm 0.40 \%$ vs. $14.40 \pm 0.46 \%, p=0.03)$.

Cholesterol serum level was significantly higher in rats receiving HFD for 12 or 24 weeks compared to those receiving the CD for the same period ( $p<0.001)$, but it was not affected by the duration of treatment. Serum and hepatic triglycerides levels were higher in HFD fed rats than in CD rats, in both groups $(p<0.001)$. In addition, a time-dependent effect was observed, as triglycerides concentration was more elevated in rats fed for 24 weeks compared to those fed for 12 weeks, in both CD and HFD groups $(p<0.001)$. A similar result was obtained by evaluating serum ALT (Table 2) as marker of hepatic function. Indeed ALT was higher $(1.18 \pm 0.01$-fold, $p<0.001)$ in rats receiving HFD for 12 or 24 weeks respect to those receiving CD for the same period, as well as in 24 weeks fed rats compared to 12 weeks in both CD and HFD groups.

TABLE 2 | Body weight and serum parameters.

\begin{tabular}{|c|c|c|c|c|}
\hline & \multicolumn{2}{|c|}{ Control } & \multicolumn{2}{|c|}{ High fat diet } \\
\hline & 12 weeks & 24 weeks & 12 weeks & 24 weeks \\
\hline Weight gain \% & $66.11 \pm 4.70^{\mathrm{a}}$ & $78.00 \pm 2.90^{a}$ & $86.12 \pm 6.20^{b}$ & $108.61 \pm 6.61^{\mathrm{C}}$ \\
\hline Cholesterol (mg/dL) & $65.17 \pm 0.75^{\mathrm{a}}$ & $66.00 \pm 1.82^{\mathrm{a}}$ & $75.00 \pm 0.92^{b}$ & $77.40 \pm 0.68^{\mathrm{b}}$ \\
\hline Triglycerides (mg/dL) & $103.7 \pm 3.43^{\mathrm{a}}$ & $118.4 \pm 4.08^{b}$ & $128.5 \pm 4.90^{b}$ & $139.6 \pm 2.06^{c}$ \\
\hline
\end{tabular}

$A L T$, alanine amino transferase. Data are the means $\pm S E$. Data with different superscripted letters are significantly different $(p<0.05)$. 


\section{Serum Level of Markers of Inflammation}

In order to study the effect of HFD diet on systemic markers of inflammation, serum TNF-alpha and Hpt levels were measured (Figure 1). TNF-alpha concentration was significantly higher $(p<0.05)$ in rats receiving HFD for 12 or 24 weeks respect to those receiving $\mathrm{CD}$ for the same period. TNF-alpha was found not to be time-dependent in $\mathrm{CD}$ group (CD 12, $0.122 \pm 0.014 \mathrm{ng} / \mathrm{mL} ; \mathrm{CD} 24,0.125 \pm 0.006 \mathrm{ng} / \mathrm{mL}$ ) or in HFD group $(0.161 \pm 0.02 \mathrm{ng} / \mathrm{mL}$; HFD 24, $0.158 \pm 0.013 \mathrm{ng} / \mathrm{mL})$.

Serum Hpt level did not differ between control and treated rats both at 12 and 24 weeks. A time-dependent trend of increase in Hpt concentration was observed (CD 12, $0.353 \pm 0.082 \mathrm{mg} / \mathrm{mL}$; CD 24, 0. $0.447 \pm 0.031 \mathrm{mg} / \mathrm{mL}$; HFD 12, $0.441 \pm 0.088 \mathrm{mg} / \mathrm{mL}$, HFD 24, $0.503 \pm 0.038 \mathrm{mg} / \mathrm{mL}$ ), although this was not significant in all groups.

It was previously demonstrated that in obese mice, which show increased serum Hpt after 12 weeks of treatment, Hpt expression was increased in WAT, but not in liver, suggesting that obesity induces a specific WAT Hpt upregulation (Lisi et al., 2011). In our experimental conditions, HFD fed rats showed a Hpt concentration 1.2-fold higher than $\mathrm{CD}$ rats, but this difference was not significant $(0.441 \pm 0.088 \mathrm{mg} / \mathrm{mL}$ vs. $0.353 \pm 0.082 \mathrm{mg} / \mathrm{mL}$ ). Conversely, serum Hpt, after 4 weeks of diet administration, was significantly higher in HFD than in $\mathrm{CD}$ rats $(0.295 \pm 0.022 \mathrm{mg} / \mathrm{mL}$ vs. $0.185 \pm 0.019 \mathrm{mg} / \mathrm{mL}$, $p=0.03$; data not shown). This led us to suppose that in our experimental model (rat fed a diet rich in lard) a significant increase of Hpt just occurs in the initial phase of treatment.

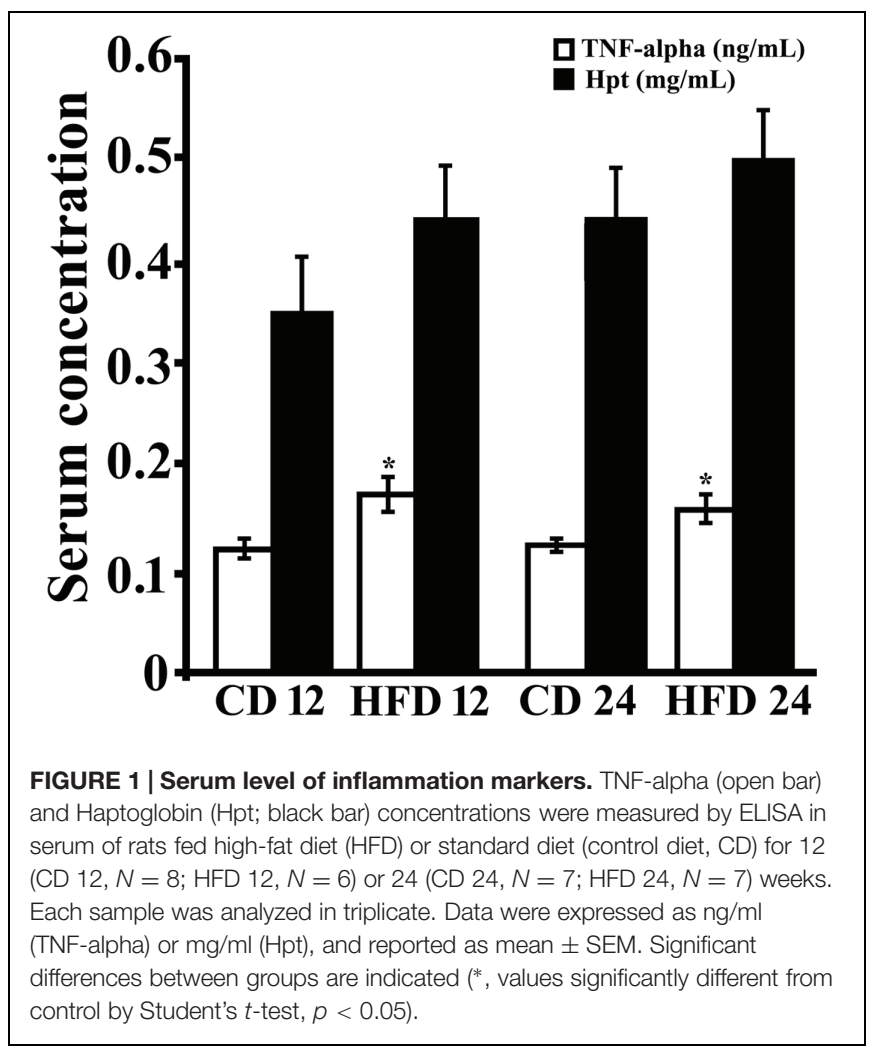

\section{TNF-Alpha Concentration in Rat Hippocampus}

TNF-alpha was titrated by sandwich ELISA, and significant diet-related changes of its level in hippocampus were observed (Figure 2). In particular, TNF-alpha concentration was about $1.5(p<0.01)$ or twofold $(p<0.001)$ higher in rats receiving HFD for 12 or 24 weeks compared to those receiving the CD for the same period. Further, we found that the duration of HFD administration did not affect hippocampal concentration of this cytokine. These results demonstrate that HFD, containing mainly lard as source of fat, induces brain inflammation, in agreement with previously published data (Thirumangalakudi et al., 2008; Wang et al., 2012), and that the effect was detectable within 12 weeks.

\section{Analysis of Hpt in Rat Hippocampus}

We previously reported that aging is associated with an increase of Hpt concentration and mRNA level in rat hippocampus (Spagnuolo et al., 2014a). As no data are available on the effect of HFD on brain expression of Hpt, we evaluated Hpt mRNA and protein levels in hippocampus of rats fed a HFD for 12 or 24 weeks. Hpt concentration, as detected by Western blotting, was significantly affected by the diet. As a matter of fact, Hpt level was lower ( $p<0.001$, Figure 3A) in hippocampus of HFD rats than in control animals, both in the group receiving the diet for 12 weeks (HFD 12, about 1.9-fold) and in 24 weeks group (HFD 24; about 3.5-fold). Further, in control animals, we found that Hpt concentration was about twofold higher $(p<0.001)$ in hippocampus of CD 24 compared with CD 12 rats, in line with our previously published data (Spagnuolo

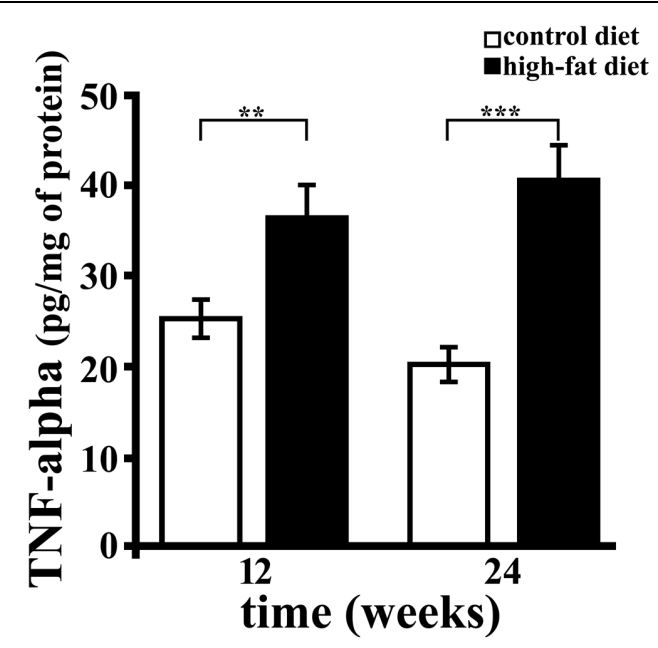

FIGURE 2 | TNF-alpha concentration in rat hippocampus. TNF-alpha was titrated by sandwich ELISA in hippocampus of rats fed high-fat diet (HFD, black bar) or standard diet (control diet, CD, open bar) for 12 or 24 weeks. Each sample was analyzed in triplicate. Data were expressed as pg per mg of protein, and are reported as mean \pm SEM. Significant differences between groups are indicated (**values significantly different from control by Student's t-test, $p<0.01$; ***values significantly different from control by Student's t-test, $p<0.001)$. 

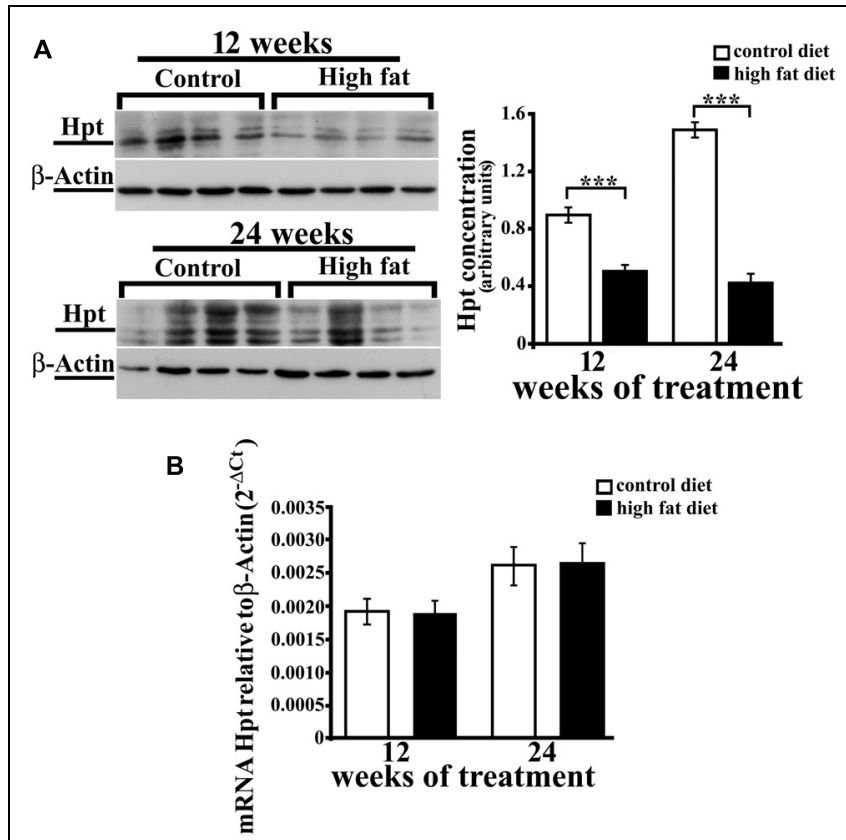

FIGURE 3 | Hpt expression in rat hippocampus. Haptoglobin protein (A) and mRNA (B) levels in hippocampus of rats fed high-fat (HFD) or standard diet (control diet, CD) for 12 or 24 weeks. (A) On the left, representative Western blots are shown. Samples were analyzed by $12.5 \%$ SDS-PAGE and western blotting. Immunocomplexes were detected by rabbit anti-Hpt and GAR-HRP IgGs. After Hpt detection, the membrane was stripped and reprobed with anti- $\beta$-actin. On the right, quantitative densitometry of $\mathrm{Hpt}$ and $\beta$-actin was carried out and band intensities were calculated. Hpt concentrations are shown relative to $\beta$-actin level. Significance of differences is shown. ***values significantly different from control by Student's $t$-test,

$p<0.001$. (B) mRNA level of Hpt is shown relative to the $\beta$-actin mRNA. The data represent the mean \pm SEM.

et al., 2014a), while the duration of HFD had no effect on Hpt concentration. Conversely, Real Time-PCR revealed no significant diet-related changes of Hpt expression (Figure 3B). An in silico analysis was performed using the RegRNA2.0 platform (http://regrna2.mbc.nctu.edu.tw/; Chang et al., 2013), and no AU-rich regions (ARE) in Hpt mRNA were found, thus suggesting that the observed diet-dependent decrease of protein concentration might be due to diet effects on Hpt synthesis and/or on Hpt stability.

\section{Analysis of $\mathrm{Hb}$ and $\mathrm{N}$-Tyr Concentration in Hippocampus}

Free $\mathrm{Hb}$ is highly toxic (Alayash, 2004), due to the presence of heme, that disrupts the lipid bilayers, and to the well known ability of iron to cause protein oxidation in vivo and in vitro $(\mathrm{Qu}$ et al., 2005). Hb was also reported to induce reactive oxygen and nitrogen species (superoxide radical and nitric oxide) production (Katsu et al., 2010; Yang et al., 2013). We therefore investigated whether HFD affects brain $\mathrm{Hb}$ concentration as well. Hb level, as assessed by ELISA, was significantly higher (about 1.8-fold, $p<0.01$ ) in hippocampus of rats receiving the HFD for 12 or 24 weeks than in rats receiving the $\mathrm{CD}$, while it was not affected by the duration of diet (Figure 4). Although a trend toward a time-dependent decrease in concentration was observed, the duration of treatment did not significantly affect hippocampal level of $\mathrm{Hb}$ neither in CD (CD 12, $0.489 \pm 0.056 \mu \mathrm{g} / \mathrm{mg}$ protein; CD 24, $0.427 \pm 0.033 \mu \mathrm{g} / \mathrm{mg}$ protein) nor in HFD group (HFD $12,0.806 \pm 0.114 \mu \mathrm{g} / \mathrm{mg}$ protein, HFD $24,0.763 \pm 0.072 \mu \mathrm{g} / \mathrm{mg}$ protein).

As known, Hpt binds with high affinity free $\mathrm{Hb}$, thus preventing $\mathrm{Hb}$-related oxidative damage and also limiting the release of heme (Quaye, 2008). The finding of higher level of $\mathrm{Hb}$ in hippocampus of $\mathrm{HFD}$ fed rats, with lower $\mathrm{Hpt}$ concentration, led us to hypothesize that the diet-dependent decrease of Hpt, which is known to act as antioxidant, might be associated with a higher extent of oxidative stress. In order to verify this hypothesis, we analyzed N-Tyr level in hippocampus of CD and HFD fed rats as marker of oxidative stress. It was previously reported that HFD administration to rats with a maternal history of HFD consumption prior to pregnancy is associated with the increase of N-Tyr level in cerebral cortex (White et al., 2009). We found that N-Tyr level was more elevated in hippocampus of HFD than in CD rats in both 12 weeks $(35.04 \pm 5.289$ vs. $22.95 \pm 2.318 \mathrm{OD} / \mathrm{mg}$ protein, $p=0.04$ ) and 24 weeks groups (41.10 \pm 7.163 vs. $19.62 \pm 2.355 \mathrm{OD} / \mathrm{mg}$ protein, $p=0.01$ ). These results support the hypothesis that HFD might induce protein oxidative damage in brain. Further, a positive correlation between $\mathrm{Hb}$ and $\mathrm{N}-\mathrm{Tyr}$ concentration was found in each group (Figure 5; CD 12, $r=0.815, p=0.014$; HFD 12, $r=0.837, p=0.038$; CD $24, r=0.855, p=0.014$; HFD 24, $r=0.786, p=0.036)$, in line with recent findings demonstrating that $\mathrm{Hb}$ induces peroxynitrite formation in vivo (Ding et al., 2014, 2015). These data suggest that HFD is accompanied by an increase of $\mathrm{Hb}$

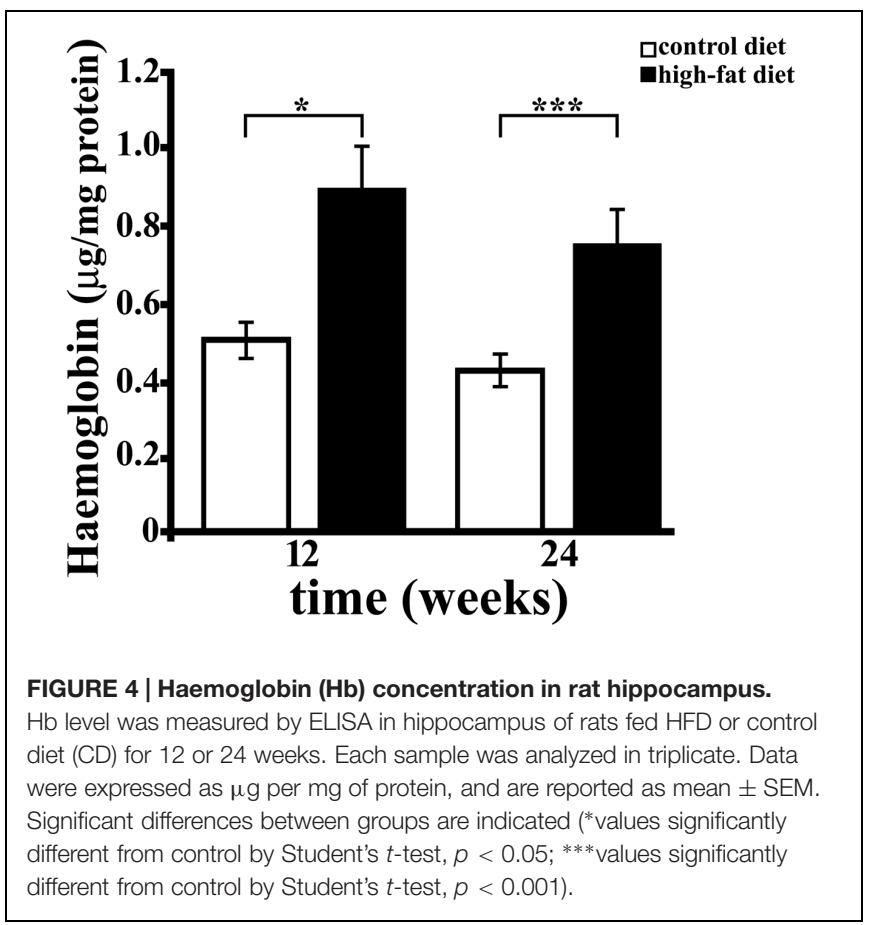




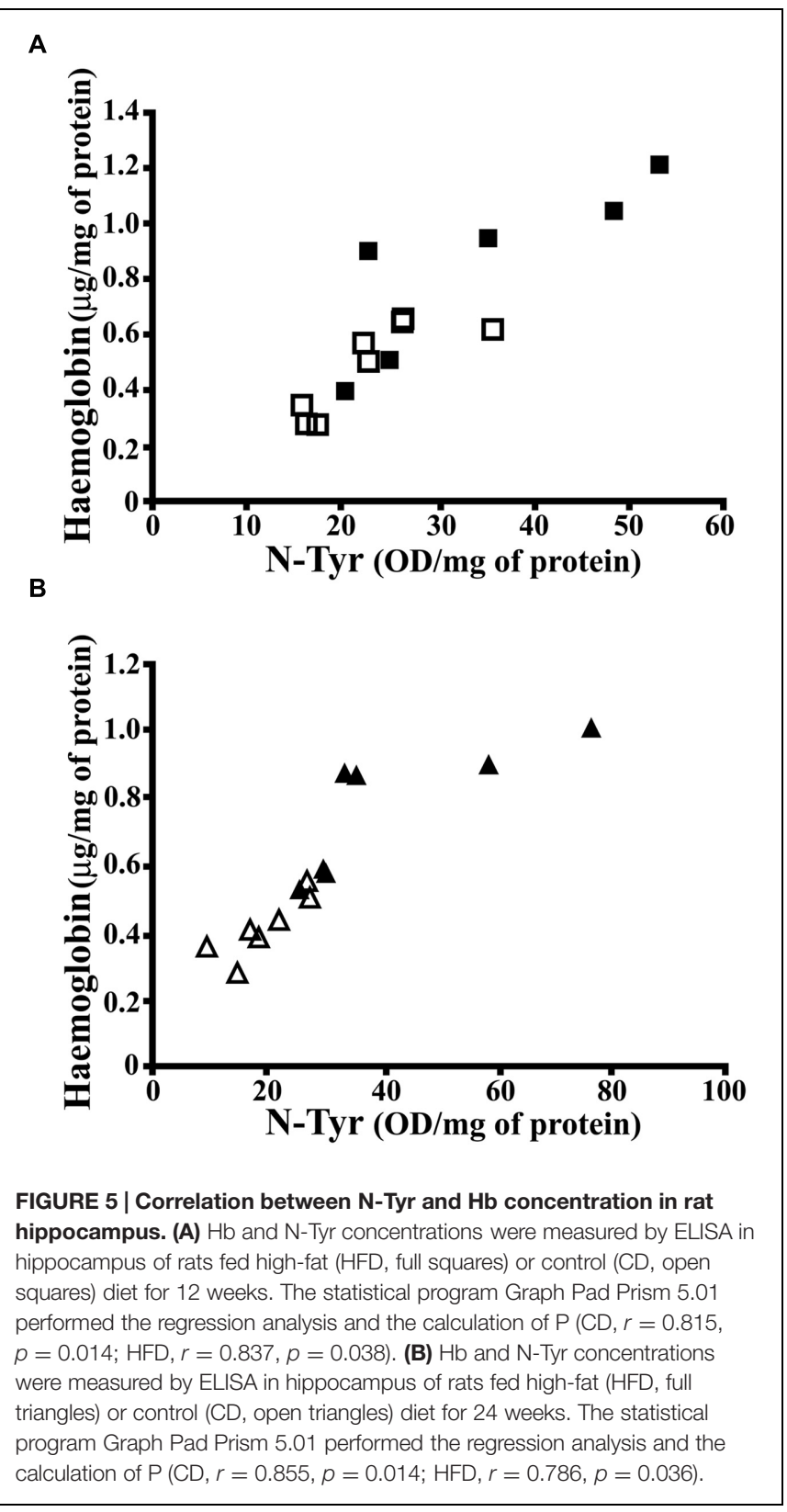

level in hippocampus which, in turn, is associated with protein oxidative modification.

\section{Cholesterol and Phospholipids Effect on Hpt Production by U-87 MG Astrocytes}

We previously demonstrated that U-87 MG astrocytes are able to synthesize and secrete Hpt (Maresca et al., 2015). As HFD was reported to alter brain lipid metabolism and composition (Freeman et al., 2014) and our results show an effect on Hpt brain level, we investigated whether Hpt production by human astrocytes can be influenced by lipid treatment. To this aim, we choose for the in vitro treatment, cholesterol, LP, and PC that in terms of fatty acids composition are similar to lard, the major component of HFD used for rats treatment. Preliminarily, the effect of these compounds on U-87 viability was evaluated by MTT assay, in order to choose lipid concentration not affecting cell survival (data not shown).

U-87 were incubated $\left(20 \mathrm{~h}, 37^{\circ} \mathrm{C}\right)$ in DMEM containing different amounts of Lipo-PC $(0,0.3,0.9,1.6$, or $3 \mu \mathrm{M})$, or free cholesterol $(0,1.5,3,6$, or $12 \mu \mathrm{g} / \mathrm{ml})$, or Lipo-LP (0; $0.1,0.3,0.9$, or $3 \mu \mathrm{M})$. After each treatment, cell culture supernatants were immunoprecipitated by monoclonal antihuman Hpt and then immunostained with polyclonal antiHpt. A significant dose-dependent decrease of $\mathrm{Hpt}$ level in supernatants from astrocyte treated with cholesterol or LipoLP was found. In particular, the amount of Hpt was reduced of about threefold by treatment with $1.5 \mu \mathrm{g} / \mathrm{ml}$ cholesterol $(p<0.001)$ and of about fourfold by treatment with $3 \mu \mathrm{g} / \mathrm{ml}$ cholesterol $(p<0.001)$. As shown in Figure 6, a sevenfold decrease $(p<0.001)$ of Hpt amount was induced by cell incubation with $12 \mu \mathrm{g} / \mathrm{ml}$ cholesterol. Lipo-LP treatment also impaired Hpt secretion, inducing a 2.5-fold decrease of Hpt level $(p<0.001)$ at the higher concentration used. Conversely, LipoPC treatment did not affect Hpt secretion. These results suggest that cholesterol and fatty acids, such as palmitic and linoleic acid, can interfere with Hpt release by U-87 MG in the extracellular compartment.

\section{DISCUSSION}

The neurodegeneration and the inflammation/obesity are becoming an inseparable binomial association. Nutrition-related effects on brain function have been extensively investigated in the last decade, and it was strongly suggested that obesity and increased consumption of HFD increase risk for development of dementia (Luchsinger et al., 2002; Hebert et al., 2003; Solfrizzi et al., 2003; Craft, 2009), although it remains to clarify the molecular mechanisms responsible for these phenomena. Oxidative stress and inflammation were suggested to play a central role in causing HFD-induced damage to the brain (Freeman et al., 2014).

To unveil the biochemical and molecular mechanisms underlying the brain consequences of dietary fats, it could be useful to identify factors that significantly change in the brain following HFD administration. Hpt represents an interesting tool to further explore the relationship between diet and inflammation in brain. Beneficial effects of this protein were already shown, since it plays a critical role in brain, defending neurons from $\mathrm{Hb}$-induced damage after intracerebral hemorrhage (Zhao et al., 2009). Also, Hpt prevents ApoE and ApoA-I oxidation (Salvatore et al., 2007, 2009), and modulates ApoE-mediated cholesterol trafficking in neuroblastoma cell lines (Spagnuolo et al., 2014a).

Here we demonstrate, for the first time, that Hpt protein level is significantly reduced in hippocampus of rats fed for a long term (until 12 or 24 weeks) a high fat diet. In contrast, Hpt mRNA did not change in response to dietary intervention. As no ARE regions, which are known to affect mRNA stability, were found in rat Hpt mRNA, differences between Real time and Western blotting results might be due to diet effects on Hpt synthesis 


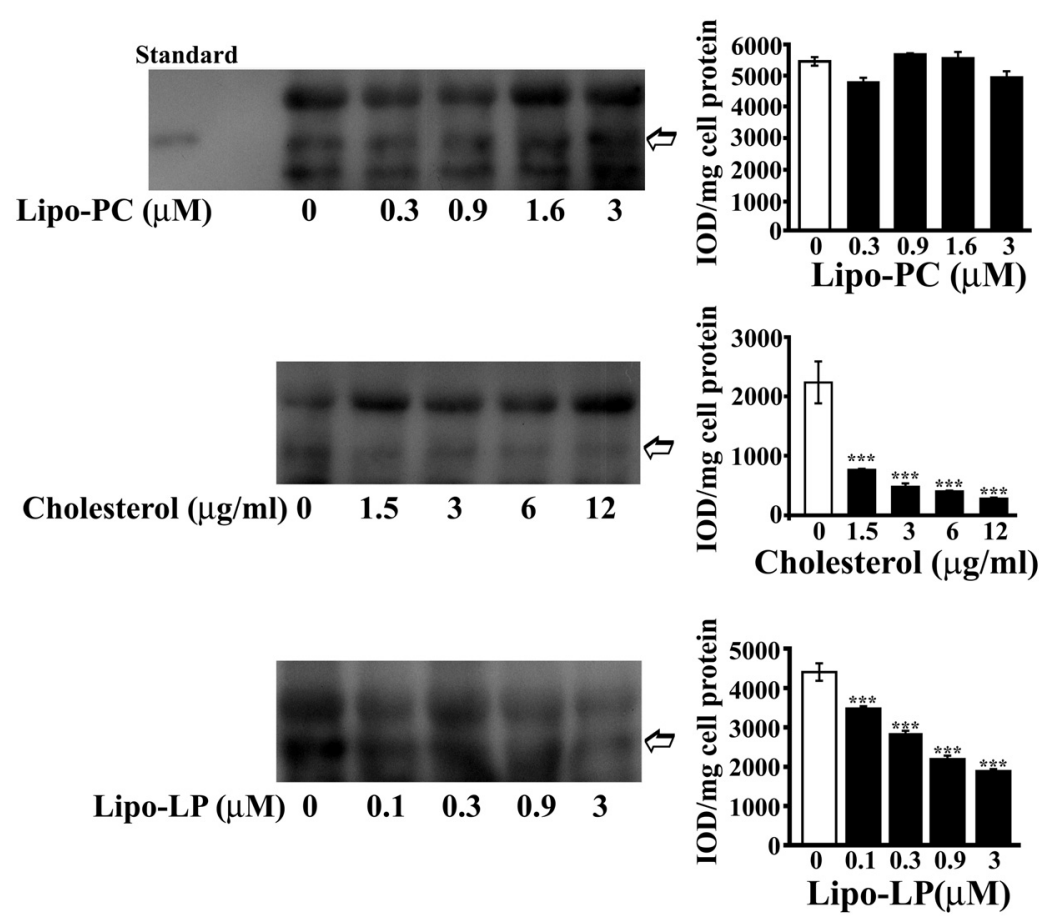

FIGURE 6 | Haptoglobin secretion by U-87 MG. U-87 MG were incubated into six well-plate (20 h; 400,000 cells/well) in DMEM containing different amounts of liposome-embedded PC (Lipo-PC; 0, 0.3, 0.9, 1.6, or $3 \mu \mathrm{M})$, or free cholesterol (0, 1.5, 3, 6, or $12 \mu \mathrm{g} / \mathrm{ml})$, or liposome embedded LP (Lipo-LP; 0, 0.1, 0.3, 0.9, or $3 \mu \mathrm{M})$. At the end of incubation, media samples were collected, immunoprecipitated with rabbit anti-human $\mathrm{Hpt}$, and finally analyzed by electrophoresis on $12.5 \%$ polyacrylamide gel, under denaturing and reducing conditions, and Western Blotting. Representative Western blotting are shown (left). Hpt in the supernatants (indicated with an arrow) was detected by mouse anti-human Hpt IgG and GAM-HRP IgG. Standard, commercial Hpt 1-1 (50 ng). Quantitative densitometry was carried out by the Gel-Pro Analyzer software (right). The intensities of the bands were measured and expressed as IOD, namely Integrated Optical Density. Band intensities (IOD) per mg of cell protein were then calculated. Significance of difference from control (cells cultured in the absence of treatment; open bar) is shown. $* * * p<0.001$.

and/or on Hpt stability. This discrepancy between mRNA and protein levels is observed for many proteins in mammalian cells, and may indicate that the modulation of HFD in the brain might be exerted mainly at the protein level (Vogel and Marcotte, 2012).

The concentration of TNF-alpha, a cytokine known to exert pleiotropic functions in central nervous system pathogenesis (McCoy and Tansey, 2008) was higher in hippocampus of highfat fed rats, thus indicating a diet-induced inflammation, which might contribute to oxidative brain injury. Indeed it was reported that inflammation is associated with the release of reactive oxygen and nitrogen species (Urrutia et al., 2014), and with the activation of inducible nitric oxide synthase (iNOS) gene in astrocytes and microglia (Possel et al., 2000; Hewett and Hewett, 2012). In this study we detected a higher amount of $\mathrm{Hb}$ in hippocampus of HFD fed rats that exhibit lower $\mathrm{Hpt}$ content, compared to $\mathrm{CD}$ fed rats. It is worth mentioning that a quote of brain $\mathrm{Hb}$ can derive from the transient extravasation of erythrocytes or from neutrophils from the peripheral circulation (Chuang et al., 2012). As accumulating evidence suggest that HFD can alter vascular components of the brain, leading to BBB disruption and dysfunction of brain endothelial cells (Freeman et al., 2014), changes to vascularization/BBB integrity might be responsible for the observed increase of cerebral $\mathrm{Hb}$. On the other hand, $\mathrm{Hb}$ was previously detected in neurons from rat brains (Richter et al., 2009; Schelshorn et al., 2009), and it was proposed it is responsible for $\mathrm{O}_{2}$ homeostasis in this area (Biagioli et al., 2009). Expression of $\mathrm{Hb}$ is enhanced by hypoxia (Schelshorn et al., 2009), and obesity-induced cerebral hypoperfusion, derived from endothelial dysfunction, was reported (Toda et al., 2014). Therefore, it cannot be excluded that the up-regulation of $\mathrm{Hb}$ that we observed might be a feedback response to hypoxia. Exogenous $\mathrm{Hb}$ released from red blood cells after traumatic brain injury or intracerebral hemorrhage is highly neurotoxic (Xi et al., 2006), and increased expression of $\mathrm{Hpt}$ was reported to protect neurons against hypoxic-ischemic injury (Zhao et al., 2009). As Hpt binds with extremely high affinity $\mathrm{Hb}$, the reduction of brain $\mathrm{Hpt}$ might be associated with an increased brain damage. By forming Hpt$\mathrm{Hb}$ complexes, Hpt stabilizes and shields heme iron within the hydrophobic pocket of $\mathrm{Hb}$, thereby preventing its prooxidative properties and cytotoxicity (Yang et al., 2003; Quaye, 2008). Indeed, excessive $\mathrm{Hb}$ and iron overload induce oxidative injury and significantly contribute to brain damage (Xi et al., 2006). Further, it was previously reported that high fat diet induces oxidative stress and endothelial dysfunction in rats, essentially by down-regulation of antioxidant enzymes, such as superoxide dismutase, catalase, glutathione peroxidase, and heme 
oxygenase-2 (HO-2; Roberts et al., 2006). So it was expected a higher extent of oxidative damage in brain of HFD fed rats. We measured N-Tyr in rat hippocampus as marker of protein oxidation induced by peroxynitrite, which, in turn, is produced by reaction of superoxide and nitric oxide. Tyrosine nitration was reported to be involved in the pathogenesis of numerous neurodegenerative disorders (Sacksteder et al., 2006; Lee et al., 2009; Yeo et al., 2015), and increased protein tyrosine nitration in aorta, kidney, heart and liver of rats, in response to HFD administration, was previously described (Roberts et al., 2000; Ghosh et al., 2006; Bautista et al., 2014). As a matter of fact we found increased levels of N-Tyr in hippocampus of HFD fed rats, likely due to the higher level of $\mathrm{Hb}$, which is known to induce superoxide radical, nitric oxide, and peroxynitrite production (Katsu et al., 2010; Yang et al., 2013; Ding et al., 2014, 2015). This pro-oxidative effect of $\mathrm{Hb}$ could be amplified by the reduction of $\mathrm{Hpt}$, the major $\mathrm{Hb}$-scavenger. Based on these data, we hypothesize that in the obese rat the metabolic activity of oligodendrocytes and astrocytes, which are the main source of Hpt in the brain (Zhao et al., 2009; Maresca et al., 2015), is altered by the HFD, and/or these cells are affected by oxidative stress and become less abundant in the brain population. In the attempt of unraveling this mechanism, we investigated the effect of cholesterol, LP or PC on Hpt synthesis by astrocytes in vitro. These molecules were chosen to mimic, also in terms of fatty acids composition, the effect of lard, which is the major component of the HFD used in this study. Our data demonstrate that Hpt secretion is significantly impaired by cholesterol or LP treatment, strongly suggesting that the release of this glycoprotein can be affected by the alteration of lipid composition of the brain.

\section{CONCLUSION}

We report evidence that the administration of HFD is associated with the decrease of $\mathrm{Hpt}$, and with the increase of $\mathrm{Hb}$ level and protein oxidative modification in hippocampus. These findings led us to hypothesize that Hpt decrease might enhance the oxidative stress induced by free $\mathrm{Hb}$. In addition, as $\mathrm{Hb}$ was shown to promote the release of inflammatory cytokines by microglia (Wang et al., 2014), we speculate that Hpt, by binding $\mathrm{Hb}$, might prevent this pro-inflammatory function. Therefore, the concomitant reduction of $\mathrm{Hpt}$ and increase of $\mathrm{Hb}$ level in brain of HFD rats might contribute to inflammatory cerebral injury. On the other hand, since Hpt actively participates in critical processes

\section{REFERENCES}

Alayash, A. I. (2004). Redox biology of blood. Antioxid. Redox Signal. 6, 941-943. doi: 10.1089/ars.2004.6.941

Bautista, R., Carreón-Torres, E., Luna-Luna, M., Komera-Arenas, Y., Franco, M., Fragoso, J. M., et al. (2014). Early endothelial nitrosylation and increased abdominal adiposity in Wistar rats after long-term consumption of food fried in canola oil. Nutrition 30, 1055-1060. doi: 10.1016/j.nut.2014.01.010

Benito-León, J., Mitchell, A. J., Hernandez-Gallego, J., and Bermejo-Pareja, F. (2013). Obesity and impaired cognitive functioning in the elderly: a population- such as immune cells recruitment, tissue repair and regeneration (Quaye, 2008), it cannot be excluded that its reduction in brain may have important implications in diet enhanced brain damage. It remains to assess whether other cerebroprotective factors, such as $\mathrm{HO}-2$, the $\mathrm{O}_{2}$ sensor in brain, that contributes to maintain neuronal physiological functions and to regulate the vascular tone of cerebral blood vessels (Parfenova and Leffler, 2008), are affected by diet administration. Nevertheless, our data, identifying Hpt as a molecule modulated in the brain by dietary fats, may represent one of the first steps in the comprehension of the molecular mechanism underlying the diet-related effects in the nervous system.

\section{AUTHOR CONTRIBUTIONS}

MSS, LC conceived and designed the research, performed cell biology and WB experiments, analyzed and interpreted all results, wrote the manuscript.

BM contributed to the planning of in vitro experiments, performed cell biology and WB experiments, analyzed data.

MPM, GC, CC, GT, MC contributed to the planning and execution of experiments with rats, analyzed data, and critically revised the manuscript.

RS contributed to the planning and execution of Real Time PCR experiments, analyzed results and critically revised the manuscript.

All authors approved the final version to be published, and ensured that questions related to the accuracy or integrity of any part of the work are appropriately investigated and resolved.

\section{FUNDING}

This research was supported partly by a grant from the University of Naples Federico II [Ricerca Dipartimentale 2012-2014] and partly by a grant from Compagnia di San Paolo [Neuroscience Program, 3868 SD/SD-2008.2487].

\section{ACKNOWLEDGMENTS}

The authors thank Dr. Emilia De Santis for the skilful management of the animal house. The authors thank Dr. Lucia Iannotta and Margherita Merola for the helpful technical assistance.

based cross-sectional study (NEDICES). Eur. J. Neurol. 20, 899-906. doi: 10.1111/ene. 12083

Biagioli, M., Pinto, M., Cesselli, D., Zaninello, M., Lazarevic, D., Roncaglia, P., et al. (2009). Unexpected expression of alpha- and beta-globin in mesencephalic dopaminergic neurons and glial cells. Proc. Natl. Acad. Sci. U.S.A. 106, 15454-15459. doi: 10.1073/pnas.0813216106

Borsody, M., Burke, A., Coplin, W., Miller-Lotan, R., and Levy, A. (2006). Haptoglobin and the development of cerebral artery vasospasm after subarachnoid hemorrhage. Neurology 66, 634-640. doi: 10.1212/01.wnl.0000200781.62172.1d 
Bradford, M. M. (1976). A rapid and sensitive method for the quantitation of microgram quantities of protein utilizing the principle of protein-dye binding. Anal. Biochem. 72, 248-254. doi: 10.1016/0003-2697(76)90527-3

Chamoun, V., Zeman, A., Blennow, K., Fredman, P., Wallin, A., Keir, G., et al. (2001). Haptoglobin as markers of blood-CSF barrier dysfunction: the findings in normal CSF. J. Neurol. Sci. 182, 117-121. doi: 10.1016/S0022-510X(00)0 0461-5

Chang, T. H., Huang, H. Y., Hsu, J. B., Weng, S. L., Horng, J. T., and Huang, H. D. (2013). An enhanced computational platform for investigating the roles of regulatory RNA and for identifying functional RNA motifs. BMC Bioinformatics 14(Suppl. 2):S4. doi: 10.1186/1471-2105-14-S2-S4

Chen, C.-H., and Albers, J. J. (1982). Characterization of proteoliposomes containing apoprotein A-I: a new substrate for the measurement of lecithin:cholesterol acyltransferase activity. J. Lipid Res. 23, 680-691.

Chiellini, C., Santini, F., Marsili, A., Berti, P., Bertacca, A., Pelosini, C., et al. (2004). Serum haptoglobin: a novel marker of adiposity in humans. J. Clin. Endocrinol. Metab. 89, 2678-2683. doi: 10.1210/jc.2003-031965

Chuang, J. Y., Lee, C. W., Shih, Y. H., Yang, T., Yu, L., and Kuo, Y. M. (2012). Interactions between amyloid- $\beta$ and hemoglobin: implications for amyloid plaque formation in Alzheimer's disease. PLoS ONE 7:e33120. doi: 10.1371/journal.pone.0033120

Cigliano, L., Pugliese, C. R., Spagnuolo, M. S., Palumbo, R., and Abrescia, P. (2009). Haptoglobin binds the antiatherogenic protein apolipoprotein E - impairment of apolipoprotein E stimulation of both lecithin:cholesterol acyltransferase activity and cholesterol uptake by hepatocytes. FEBS J. 276, 6158-6171. doi: 10.1111/j.1742-4658.2009.07319.x

Cocciolo, A., Di Domenico, F., Coccia, R., Fiorini, A., Cai, J., Pierce, W. M., et al. (2012). Decreased expression and increased oxidation of plasma haptoglobin in Alzheimer disease: insights from redox proteomics. Free Radic. Biol. Med. 53, 1868-1876. doi: 10.1016/j.freeradbiomed.2012.08.596

Craft, S. (2009). The role of metabolic disorders in Alzheimer disease and vascular dementia: two roads converged. Arch. Neurol. 66, 300-305. doi: 10.1001/archneurol.2009.27

Ding, R., Chen, Y., Yang, S., Deng, X., Fu, Z., Feng, L., et al. (2014). Bloodbrain barrier disruption induced by hemoglobin in vivo: involvement of upregulation of nitric oxide synthase and peroxynitrite formation. Brain Res. 1571, 25-38. doi: 10.1016/j.brainres.2014.04.042

Ding, R., Feng, L., He, L., Chen, Y., Wen, P., Fu, Z., et al. (2015). Peroxynitrite decomposition catalyst prevents matrix metalloproteinase- 9 activation and neurovascular injury after hemoglobin injection into the caudate nucleus of rats. Neuroscience 297, 182-193. doi: 10.1016/j.neuroscience.2015. 03.065

Elias, M. F., Elias, P. K., Sullivan, L. M., Wolf, P. A., and D’Agostino, R. B. (2003), Lower cognitive function in the presence of obesity and hypertension: the Framingham Heart Study. Int. J. Obes. Relat. Metab. Disord. 27, 260-268. doi: 10.1038/sj.ijo.802225

Freeman, L. R., Haley-Zitlin, V., Rosenberger, D. S., and Granholm, A. C. (2014). Damaging effects of a high-fat diet to the brain and cognition: a review of proposed mechanisms. Nutr. Neurosci. 17, 241-251. doi: 10.1179/1476830513Y.0000000092

Friedrichs, W. E., Navarijo-Ashbaugh, A. L., Bowman, B. H., and Yang, F. (1995). Expression and inflammatory regulation of haptoglobin gene in adipocytes. Biochem. Biophys. Res. Commun. 209, 250-256. doi: 10.1006/bbrc.1995. 1496

Ghosh, S., Kewalramani, G., Yuen, G., Pulinilkunnil, T., An, D., Innis, S. M., et al. (2006). Induction of mitochondrial nitrative damage and cardiac dysfunction by chronic provision of dietary omega-6 polyunsaturated fatty acids. Free Radic. Biol. Med. 41, 1413-1424. doi: 10.1016/j.freeradbiomed.2006.07.021

Gómez-Isla, T., Price, J. L., Mckeel, D. W. Jr., Morris, J. C., Growdon, J. H., and Hyman, B. T. (1996). Profound loss of layer II entorhinal cortex neurons occurs in very mild Alzheimer's disease. J. Neurosci. 16, 4491-4500.

Gustafson, D. (2008). A life course of adiposity and dementia. Eur. J. Pharmacol. 585, 163-175. doi: 10.1016/j.ejphar.2008.01.052

Haslam, D. W., and James, W. P. (2005). Obesity. Lancet Neurol. 366, 1197-1209. doi: 10.1016/S0140-6736(05)67483-1

Hebert, L. E., Scherr, P. A., Bienias, J. L., Bennett, D. A., and Evans, D. A. (2003). Alzheimer disease in the US population: prevalence estimates using the 2000 census. Arch. Neurol. 60, 1119-1122. doi: 10.1001/archneur.60.8.1119
Hewett, J. A., and Hewett, S. J. (2012). Induction of nitric oxide synthase-2 expression and measurement of nitric oxide production in enriched primary cortical astrocyte cultures. Methods Mol. Biol. 814, 251-263. doi: 10.1007/9781-61779-452-0_17

Hsu, T. M., and Kanoski, S. E. (2014). Blood-brain barrier disruption: mechanistic links between Western diet consumption and dementia. Front. Aging Neurosci. 6:88. doi: 10.3389/fnagi.2014.00088

Iossa, S., Mollica, M. P., Lionetti, L., Crescenzo, R., Botta, M., and Liverini, G. (2002). Skeletal muscle oxidative capacity in rats fed high-fat diet. Int. J. Obes. Relat. Metab. Disord. 26, 65-72. doi: 10.1038/sj.ijo.08 01844

Johnson, G., Brane, D., Block, W., van Kammen, D. P., Gurklis, J., Peters, J. L., et al. (1992). Cerebrospinal fluid protein variations in common to Alzheimer's disease and schizophrenia. Appl. Theor. Electrophor. 3, 47-53.

Kalmijn, S. (2000). Fatty acid intake and the risk of dementia and cognitive decline: a review of clinical and epidemiological studies. J. Nutr. Health Aging 4, 202-207.

Kalmijn, S., Launer, L. J., Ott, A., Witteman, J. C., Hofman, A., and Breteler, M. M. (1997). Dietary fat intake and the risk of incident dementia in the Rotterdam study. Ann. Neurol. 42, 776-782. doi: 10.1002/ana.410420514

Katsu, M., Niizuma, K., Yoshioka, H., Okami, N., Sakata, H., and Chan, P. H. (2010). Hemoglobin-induced oxidative stress contributes to matrix metalloproteinase activation and blood-brain barrier dysfunction in vivo. J. Cereb. Blood Flow Metab. 30, 1939-1950. doi: 10.1038/jcbfm.2010.45

La Marca, V., Spagnuolo, M. S., Cigliano, L., Marasco, D., and Abrescia, P. (2014). The enzyme lecithin-cholesterol acyltransferase esterifies cerebrosterol and limits the toxic effect of this oxysterol on SH-SY5Y cells. J. Neurochem. 130, 97-108. doi: 10.1111/jnc. 12713

Lee, J. R., Kim, J. K., Lee, S. J., and Kim, K. P. (2009). Role of protein tyrosine nitration in neurodegenerative diseases and atherosclerosis. Arch. Pharm. Res. 32, 1109-1118. doi: 10.1007/s12272-009-1802-0

Lee, M. Y., Kim, S. Y., Choi, J. S., Lee, I. H., Choi, Y. S., Jin, J. Y., et al. (2002). Upregulation of haptoglobin in reactive astrocytes after transient forebrain ischemia in rats. J. Cereb. Blood Flow Metab. 22, 1176-1180. doi: 10.1097/00004647-200210000-00004

Lisi, S., Gamucci, O., Vottari, T., Scabia, G., Funicello, M., Marchi, M., et al. (2011). Obesity-associated hepatosteatosis and impairment of glucose homeostasis are attenuated by haptoglobin deficiency. Diabetes 60, 2496-2505. doi: $10.2337 / \mathrm{db} 10-1536$

Luchsinger, J. A., Tang, M. X., Shea, S., and Mayeux, R. (2002). Caloric intake and the risk of Alzheimer disease. Arch. Neurol. 59, 1258-1263. doi: 10.1001/archneur.59.8.1258

Malnick, S. D., and Knobler, H. (2006). The medical complications of obesity. QJM 99, 565-579. doi: 10.1093/qjmed/hcl085

Maresca, B., Spagnuolo, M. S., and Cigliano, L. (2015). Haptoglobin modulates beta-amyloid uptake by U-87 MG astrocyte cell line. J. Mol. Neurosci. 56, 35-47. doi: 10.1007/s12031-014-0465-6

Mattson, M. P., Duan, W., and Guo, Z. (2003). Meal size and frequency affect neuronal plasticity and vulnerability to disease: cellular and molecular mechanisms. J. Neurochem. 84, 417-431. doi: 10.1046/j.1471-4159.2003. 01586.x

McCoy, M. K., and Tansey, M. G. (2008). TNF signaling inhibition in the CNS: implications for normal brain function and neurodegenerative disease. J. Neuroinflammation 5:45. doi: 10.1186/1742-2094-5-45

Morris, M. C., Evans, D. A., Bienias, J. L., Tangney, C. C., Bennett, D. A., Aggarwal, N., et al. (2003). Dietary fats and the risk of incident Alzheimer disease. Arch. Neurol. 60, 194-200. doi: 10.1001/archneur.60.2.194

Morris, M. C., Evans, D. A., Bienias, J. L., Tangney, C. C., and Wilson, R. S. (2004). Dietary fat intake and 6-year cognitive change in an older biracial community population. Neurology 62, 1573-1579. doi: 10.1212/01.WNL.0000123250.82849.B6

Parfenova, H., and Leffler, C. W. (2008). Cerebroprotective functions of HO-2. Curr. Pharm. Des. 14, 443-453. doi: 10.2174/1381612087835 97380

Pistell, P. J., Morrison, C. D., Gupta, S., Knight, A. G., Keller, J. N., Ingram, D. K., et al. (2010). Cognitive impairment following high fat diet consumption is associated with brain inflammation. J. Neuroimmunol. 219, 25-32. doi: 10.1016/j.jneuroim.2009.11.010 
Possel, H., Noack, H., Putzke, J., Wolf, G., and Sies, H. (2000). Selective upregulation of inducible nitric oxide synthase (iNOS) by lipopolysaccharide (LPS) and cytokines in microglia: in vitro and in vivo studies. Glia 32, 51-59.

Powers, J. M., Schlaepfer, W. W., Willingham, M. C., and Hall, B. J. (1981). An immunoperoxidase study of senile cerebral amyloidosis with pathogenetic considerations. J. Neuropathol. Exp. Neurol. 40, 592-612. doi: 10.1097/00005072-198105000-00043

Price, J. L., Ko, A. I., Wade, M. J., Tsou, S. K., Mckeel, D. W., and Morris, J. C. (2001). Neuron number in the entorhinal cortex and CA1 in preclinical Alzheimer disease. Arch. Neurol. 58, 1395-1402. doi: 10.1001/archneur.58.9.1395

Qu, Y., Chen, J., Benvenisti-Zarom, L., Ma, X., and Regan, R. F. (2005). Effect of targeted deletion of the heme oxygenase-2 gene on hemoglobin toxicity in the striatum. J. Cereb. Blood Flow Metab. 25, 1466-1475. doi: 10.1038/sj.jcbfm.9600143

Quaye, I. K. (2008). Haptoglobin, inflammation and disease. Trans. R. Soc. Trop. Med. Hyg. 102, 735-742. doi: 10.1016/j.trstmh.2008.04.010

Reinert, K. R., Po'e, E. K., and Barkin, S. L. (2013). The relationship between executive function and obesity in children and adolescents: a systematic literature review. J. Obes. 2013:820956. doi: 10.1155/2013/820956

Richter, F., Meurers, B. H., Zhu, C., Medvedeva, V. P., and Chesselet, M. F. (2009). Neurons express hemoglobin $\alpha$ - and $\beta$-chains in rat and human brains. J. Comp. Neurol. 515, 538-547. doi: 10.1002/cne.22062

Roberts, C. K., Barnard, R. J., Sindhu, R. K., Jurczak, M., Ehdaie, A., and Vaziri, N. D. (2006). Oxidative stress and dysregulation of NAD(P)H oxidase and antioxidant enzymes in diet-induced metabolic syndrome. Metabolism 55, 928-934. doi: 10.1016/j.metabol.2006.02.022

Roberts, C. K., Vaziri, N. D., Wang, X. Q., and Barnard, R. J. (2000). Enhanced NO inactivation and hypertension induced by a high-fat, refined-carbohydrate diet. Hypertension 36, 423-429. doi: 10.1161/01.HYP.36.3.423

Sacksteder, C. A., Qian, W. J., Knyushko, T. V., Wang, H., Chin, M. H., Lacan, G., et al. (2006). Endogenously nitrated proteins in mouse brain: links to neurodegenerative disease. Biochemistry 45, 8009-8022. doi: 10.1021/bi060474w

Salvatore, A., Cigliano, L., Bucci, E. M., Corpillo, D., Velasco, S., Carlucci, A., et al. (2007). Haptoglobin binding to apolipoprotein A-I prevents damage from hydroxyl radicals on its stimulatory activity of the enzyme lecithincholesterol acyl-transferase. Biochemistry 46, 11158-11168. doi: 10.1021/bi700 6349

Salvatore, A., Cigliano, L., Carlucci, A., Bucci, E. M., and Abrescia, P. (2009). Haptoglobin binds apolipoprotein $\mathrm{E}$ and influences cholesterol esterification in the cerebrospinal fluid. J. Neurochem. 110, 255-263. doi: 10.1111/j.14714159.2009.06121.x

Schelshorn, D. W., Schneider, A., Kuschinsky, W., Weber, D., Krüger, C., Dittgen, T., et al. (2009). Expression of hemoglobin in rodent neurons. J. Cereb. Blood Flow Metab. 29, 585-595. doi: 10.1038/jcbfm.2008.152

Sellbom, K. S., and Gunstad, J. (2012). Cognitive function and decline in obesity. J. Alzheimers Dis. 30, S89-S95. doi: 10.3233/JAD-2011-111073

Solfrizzi, V., Panza, F., and Capurso, A. (2003). The role of diet in cognitive decline. J. Neural Transm. 110, 95-110.

Souza, C. G., Moreira, J. D., Siqueira, I. R., Pereira, A. G., Rieger, D. K., Souza, D. O., et al. (2007). Highly palatable diet consumption increases protein oxidation in rat frontal cortex and anxiety-like behavior. Life Sci. 81, 198-203. doi: 10.1016/j.lfs.2007.05.001

Spagnuolo, M. S., Maresca, B., Mollica, M. P., Cavaliere, G., Cefaliello, C., Trinchese, G., et al. (2014a). Haptoglobin increases with age in rat hippocampus and modulates Apolipoprotein E mediated cholesterol trafficking in neuroblastoma cell lines. Front. Cell. Neurosci. 8:212. doi: $10.3389 /$ fncel.2014.00212

Spagnuolo, M. S., Maresca, B., La Marca, V., Carrizzo, A., Veronesi, C., Cupidi, C., et al. (2014b). Haptoglobin interacts with apolipoprotein E and betaamyloid and influences their crosstalk. ACS Chem. Neurosci. 5, 837-847. doi: $10.1021 / \mathrm{cn} 500099 \mathrm{f}$

Thambisetty, M. (2010). Do extracellular chaperone proteins in plasma have potential as Alzheimer's disease biomarkers? Biomark. Med. 4, 831-834. doi: $10.2217 /$ bmm.10.108

Thirumangalakudi, L., Prakasam, A., Zhang, R., Bimonte-Nelson, H., Sambamurti, K., Kindy, M. S., et al. (2008). High cholesterol-induced neuroinflammation and amyloid precursor protein processing correlate with loss of working memory in mice. J. Neurochem. 106, 475-485. doi: 10.1111/j.1471-4159.2008.05415.x

Toda, N., Ayajiki, K., and Okamura, T. (2014). Obesity-induced cerebral hypoperfusion derived from endothelial dysfunction: one of the risk factors for Alzheimer's disease. Curr. Alzheimer Res. 11, 733-744. doi: 10.2174/156720501108140910120456

Urrutia, P. J., Mena, N. P., and Núñez, M. T. (2014). The interplay between iron accumulation, mitochondrial dysfunction, and inflammation during the execution step of neurodegenerative disorders. Front. Pharmacol. 5:38. doi: 10.3389/fphar.2014.00038

Veerhuis, R., Van Breemen, M. J., Hoozemans, J. M., Morbin, M., Ouladhadj, J., Tagliavini, F., et al. (2003). Amyloid beta plaque-associated proteins $\mathrm{C} 1 \mathrm{q}$ and SAP enhance the Abetal-42 peptide-induced cytokine secretion by adult human microglia in vitro. Acta Neuropathol. 105, 135-144.

Vogel, C., and Marcotte, E. M. (2012). Insights into the regulation of protein abundance from proteomic and transcriptomic analyses. Nat. Rev. Genet. 13, 227-232. doi: 10.1038/nrg3185

Wang, X., Ge, A., Cheng, M., Guo, F., Zhao, M., Zhou, X., et al. (2012). Increased hypothalamic inflammation associated with the susceptibility to obesity in rats exposed to high-fat diet. Exp. Diabetes Res. 2012:847246. doi: $10.1155 / 2012 / 847246$

Wang, Y. C., Zhou, Y., Fang, H., Lin, S., Wang, P. F., Xiong, R. P., et al. (2014). Toll-like receptor $2 / 4$ heterodimer mediates inflammatory injury in intracerebral hemorrhage. Ann. Neurol. 75, 876-889. doi: 10.1002/ana. 24159

White, C. L., Pistell, P. J., Purpera, M. N., Gupta, S., Fernandez-Kim, S. O., Hise, T. L., et al. (2009). Effects of high fat diet on Morris maze performance, oxidative stress, and inflammation in rats: contributions of maternal diet. Neurobiol. Dis. 35, 3-13. doi: 10.1016/j.nbd.2009.04.002

Wilson, M. R., Yerbury, J. J., and Poon, S. (2008). Potential roles of abundant extracellular chaperones in the control of amyloid formation and toxicity. Mol. Biosyst. 4, 42-52. doi: 10.1039/B712728F

Xi, G., Keep, R. F., and Hoff, J. T. (2006). Mechanisms of brain injury after intracerebral haemorrhage. Lancet Neurol. 5, 53-63. doi: 10.1016/S14744422(05)70283-0

Yang, F., Haile, D. J., Berger, F. G., Herbert, D. C., Van Beveren, E., and Ghio, A. J. (2003). Haptoglobin reduces lung injury associated with exposure to blood. Am. J. Physiol. Lung Cell. Mol. Physiol. 284, L402-L409. doi: 10.1152/ajplung.00115.2002

Yang, S., Chen, Y., Deng, X., Jiang, W., Li, B., Fu, Z., et al. (2013). Hemoglobininduced nitric oxide synthase overexpression and nitric oxide production contribute to blood-brain barrier disruption in the rat. J. Mol. Neurosci. 51, 352-363. doi: 10.1007/s12031-013-9990-y

Yeo, W. S., Kim, Y. J., Kabir, M. H., Kang, J. W., Ahsan-Ul-Bari, M., and Kim, K. P. (2015). Mass spectrometric analysis of protein tyrosine nitration in aging and neurodegenerative diseases. Mass Spectrom. Rev. 34, 166-183. doi: 10.1002/mas.21429

Yerbury, J. J., Kumita, J. R., Meehan, S., Dobson, C. M., and Wilson, M. R. (2009). a2-Macroglobulin and haptoglobin suppress amyloid formation by interacting with prefibrillar protein species. J. Biol. Chem. 284, 4246-4254. doi: 10.1074/jbc.M807242200

Yerbury, J. J., Rybchyn, M. S., Easterbrook-Smith, S. B., Henriques, C., and Wilson, M. R. (2005). The acute phase protein haptoglobin is a mammalian extracellular chaperone with an action similar to clusterin. Biochemistry 44, 10914-10925. doi: 10.1021/bi050764x

Yerbury, J. J., and Wilson, M. R. (2010). Extracellular Chaperones modulate the effects of Alzheimer's patient cerebrospinal fluid on Ab1-42 toxicity and uptake. Cell Stress Chaperones 15, 115-121. doi: 10.1007/s12192-009-0122-0

Zhang, J., McKeown, R. E., Muldoon, M. F., and Tang, S. (2006). Cognitive performance is associated with macronutrient intake in healthy young and middle-aged adults. Nutr. Neurosci. 9, 179-187. doi: $10.1080 / 10284150600955172$

Zhang, X., Dong, F., Ren, J., Driscoll, M. J., and Culver, B. (2005). High dietary fat induces NADPH oxidase-associated oxidative stress and inflammation in rat cerebral cortex. Exp. Neurol. 191, 318-325. doi: 10.1016/j.expneurol.2004.10.011 
Zhao, X., Song, S., Sun, G., Strong, R., Zhang, J., Grotta, J. C., et al. (2009). Neuroprotective role of haptoglobin after intracerebral hemorrhage. J. Neurosci. 29, 15819-15827. doi: 10.1523/JNEUROSCI.3776-09.2009

Conflict of Interest Statement: The authors declare that the research was conducted in the absence of any commercial or financial relationships that could be construed as a potential conflict of interest.
Copyright (c) 2015 Spagnuolo, Mollica, Maresca, Cavaliere, Cefaliello, Trinchese, Scudiero, Crispino and Cigliano. This is an open-access article distributed under the terms of the Creative Commons Attribution License (CC BY). The use, distribution or reproduction in other forums is permitted, provided the original author(s) or licensor are credited and that the original publication in this journal is cited, in accordance with accepted academic practice. No use, distribution or reproduction is permitted which does not comply with these terms. 